\title{
A representação feminina (migrante) no acervo da Fondation Lovis Vuitton: um debate sobre trajetórias artísticas e a produção de legitimidade
}

Henrique Grimaldi Figueredo'

\section{Resumo}

Neste artigo focalizaremos alguns debates sobre os métodos de consagração e êxito de carreiras artísticas contemporâneas a partir dos processos de legitimação e elaboração da crença. Cruzando debates teóricos e análise empírica, refletimos sobre a carreira de três mulheres artistas migrantes no acervo da Fondation Louis Vuitton, em Paris, e os critérios de reconhecimento e validação de suas obras.

Palavras-Chave: consagração artística; Fondation Louis Vuitton; arte contemporânea; mulheres migrantes.

Abstract

In this article we will focus on some debates on the methods of consecration and success of contemporary artistic careers based on the processes of legitimation and elaboration of belief. Based on a cross between theoretical debates and empirical analysis, we reflected on the career of three

\footnotetext{
1 Doutorando em Sociologia pelo Instituto de Filoso a e Ciências Humanas da Universidade Estadual de Campinas (IFCH/UNICAMP). Bolsista da Fundação de Amparo à Pesquisa do Estado de São Paulo (Fapesp) bolsa 2019/10315-5 e editor executivo do periódico Todas as Artes - Revista Luso-Brasileira de Artes e Cultura, sediado no Instituto de Sociologia da Universidade do Porto, Portugal. Encontra-se atualmente como pesquisador visitante na École des Hautes Études en Sciences Sociales (EHESS), França (2021-2022), com bolsa Fapesp 2020/02298-0. ORCID: 0000-0002-6324-4876. E-mail: henriquegrimaldi gueredo@outlook.com.
} 
women artists in the collection of the Fondation Louis Vuitton, in Paris, and the criteria for the recognition and validation of their works.

Keywords: artistic consecration; Fondation Louis Vuitton; contemporary art; migrant women.

\section{Introdução}

A noção de êxito na arte contemporânea firmou-se na última década como um profícuo campo de debate sociológico. Refletir sobre a construção do sucesso artístico deflagra não só as problemáticas e os discursos vigentes no campo das artes, mas a própria construção social de um gosto e de uma cultura legitimada. Tema complexo, a noção de êxito vem sendo abordada sob diferentes perspectivas que buscam demonstrar os processos eficazes de elaboração dos valores artísticos inscritos em um campo relativamente autônomo. Uma tendência comum entre essas abordagens é computar uma extensa rede de agentes e instituições como promotoras desses respectivos valores, e sobretudo, o papel do mercado de arte nessas novas narrativas. Nathalie Moureau descreve as variações entre relevância artística e precificação através do papel dos colecionadores (MOUREAU, 2020). Já o sociólogo francês Alain Quemin, parte de uma análise geográfica dos espaços e discursos legitimados sobre o fazer artístico para cartografar a produção de uma dada consagração (QUEMIN, 2016). Por sua vez, o sociólogo holandês Olav Velthius (2007) descreve uma justaposição entre práticas visíveis e invisíveis, onde o valor - e o preço constroem-se também na disposição interpessoal - e muitas vezes inacessível - dos próprios agentes, grafando dinâmicas próprias e simultâneas entre espaço público (front desk) e privado (back office).

Evidentemente, cada um desses trabalhos contribui a uma compreensão efetiva dos processos de consagração artística. O que 
pretendemos aqui é - alicerçados por estas variações - colaborar com estes debates focalizando, por vez, a superposição entre instâncias geográficas e valores simbólicos. Para tanto, discutiremos inicialmente as assimetrias constitutivas do universo da arte contemporânea e como os valores artísticos são, com efeito, elaborados dentro de uma noção expandida e discursiva - do campo artístico. Empiricamente trabalhando a partir de um recorte de gênero, isto é, artistes colecionadas ${ }^{1}$ pela Fondation Louis Vuitton, em Paris - um museu privado que vem se consolidando como um espaço altamente legitimado na arte contemporânea mundial - perfilaremos algumas carreiras artísticas de sucesso utilizando como variáveis seus locais de nascimento, locais de formação, galerias pelas quais são representadas e a recorrência em coleções e prêmios, ilustrando, assim, a problemática do acúmulo de capitais - sociais, educacionais, etc. - como modo de adentrar ao jogo da arte (BOURDIEU, 1996). É preciso salientar que não trataremos das temáticas das obras nem de qualquer discussão acerca da qualidade estética de seus trabalhos, ao contrário, direcionaremos nossa atenção exclusivamente ao desbravamento de um dado campo discursivo pautado na disposição teórica que argumenta que o acesso aos procedimentos de elaboração de um conceito deve ser realizado na investigação do campo narrativo onde este é desenvolvido (FOUCAULT, 1971).

\section{Um mundo de assimetrias: globalização versus mundialização}

Temática incontornável nos debates sociológicos da cultura, as singularidades entre globalização e mundialização firmam-se, de fato, como um modo de leitura profícuo das assimetrias materiais e simbólicas operantes no universo das artes. Certamente essa distinção - como trabalhada pelo sociólogo Renato Ortiz (1998) - versa sobre as variações constitutivas de todo universo cultural, mas podem aqui ser aplicadas como lente teórica na compreensão dos istmos hierárquicos mantidos entre agentes, lugares,

$1 \quad$ Artistes que se identificam como mulheres. 
instituições e mercados próprios a um determinado campo narrativo, isto é, as artes visuais, particularmente após a virada do milênio.

Ortiz delimita tal distinção frente à noção equivocada de que a globalização seria promotora de uma homogeneização dos processos em escala global. Embora passível de uma tradução do ponto de vista econômico, dificilmente tal feito repete-se a nível cultural. A relação entre a distribuição do capital e o poder político da cultura encontra-se, no contexto globalizado, sob um regime de complementariedade mas não simultaneidade; isto é, economia e cultura são campos que reagem de formas diferentes à globalização, e embora seja possível identificarmos influências entre estas dimensões, sua organicidade é distinta (ORTIZ, 1998). O sociólogo classificará esta dimensão ao propor uma distinção entre globalização e mundialização. A ideia de globalização estaria atrelada a uma homogeneização ou unicidade aplicáveis aos domínios econômicos ou tecnológicos. A cultura, por outro lado, se ramificaria de modo diverso; diferentemente da economia e da tecnologia, passíveis de serem percebidas a uma lógica realmente globalizada, a cultura não se enquadraria neste formato: não há, de fato, uma cultura globalizada, esta deve ser compreendida sob uma lógica outra, a da mundialização. Ao analisarmos esse itinerário sob o que Ortiz (2000) define por modernidade-mundo, nos deparamos com uma composição heterogênea, uma dinâmica espacial transnacional, na qual capital e cultura se distribuem de maneira assimétrica.

Além da compreensão da mundialização dos mercados culturais, outros dois conceitos desenvolvidos por Ortiz são também necessários para o problema aqui analisado: standard (tradução) e pattern (padrão). A definição de standard associa-se aos processos de serialização dos bens culturais, enquanto os pattern correspondem ao conjunto de normatizações estruturalizantes das relações sociais, hierarquizando e legitimando alguns padrões em detrimento de outros. Tais movimentos poderiam ser correspondentes ao que Bourdieu define como produção da crença, na qual a credibilidade em determinados bens ou objetos da cultura é produzida 
através da "crença coletiva como desconhecimento coletivo, coletivamente produzido e reproduzido" (BOURDIEU, 1996, p. 198); isto é, a obra ou os bens culturais têm sua legitimidade assegurada por padrões estabelecidos por agentes e instituições específicas, simbolicamente autorizados a proferirem tais discursos.

Focalizando o universo da produção artística sob essa perspectiva, torna-se patente o fato de que há a manutenção de uma hierarquia discursiva, e embora seja perceptível o crescimento da circulação de artistas nas últimas décadas, permanece o esforço do próprio campo em gerir e estabilidade de seus núcleos duros: os lugares irradiadores da crença e das narrativas, que por seu acúmulo de capitais - sociais, simbólicos, econômicos e artísticos - preservam, mesmo que vez ou outra contestados por experiências disruptivas, uma intangível baliza da "arte de qualidade". Assim, se tomarmos o conceito de campo artístico como recuperado por Simioni (2017), no qual esse formaliza-se através de suas disputas - onde o campo é um campo de forças cuja distribuição e intensidade são análogas à produção de uma certa autoridade - veremos que este espaço metafórico encarna-se, portanto, como um espaço estruturalizado de relações objetivas, através das quais agentes, instituições e grupos específicos disputam o monopólio discursivo de definição dos conceitos artísticos, operacionalizando os modos de legitimação e apreciação da arte.

Embora a maior circulação geográfica de artistas e de suas criações transpareça uma mitológica simetria das relações, as forças narrativas vigentes sofrem poucas ou insignificantes alterações determinando, em consequência, a produção das obras de arte, carreiras artísticas e tendências estéticas contemporâneas a partir de uma legitimidade discursiva que é ela própria homóloga aos campos de poder. Não queremos dizer com isso que experiências provocativas ou contestadoras sejam possíveis apenas como mecanismo de fricção para adentrar o campo (em suas bordas), mas sim que a tradição e o acúmulo de capitais no campo artístico atuam como ferramentas eficazes de legitimação da arte sendo, por vezes, emulados por 
ações extracampo em sua operação de disputa ou concorrência frente às dinâmicas da arte mundial.

Logo, no modelo assimétrico da distribuição da autoridade, uma instituição de médio porte e no interior de um país dito periférico teria menos capacidade narrativa que uma instituição do interior da França, por exemplo, e esta por sua vez, menos poder de legitimação que um museu reconhecido e mundializado em Paris. $O$ mesmo replica-se quando tratamos dos artistas. Formar-se e trabalhar em um grande polo irradiador de arte como Paris, Londres, Nova York ou Berlim, provavelmente terá um papel preponderante na construção de uma ideia de êxito, profissionalização ou seriedade do trabalho desses atores. Não despropositadamente Thompson (2008) e Woodham ${ }^{2}$ (2017) nos falam sobre as imensas comunidades artísticas em Londres ou Nova York disputando sua entrada nos liames da arte legitimada: uma massa formada por agentes autodeslocados para essas cidades em busca de reconhecimento e estreitamento com o mercado e as instituições.

Se a globalização das tecnologias e do mercado facilita a circulação dos ativos e de pessoas, a assimetria da distribuição do poder discursivo da arte ratifica uma centralização das práticas em alguns lugares bastante específicos: grosso modo, para alcançar uma relevância social, o artista independentemente de sua origem geográfica - deve preencher alguns requisitos (passar por algumas escolas; expor em galerias específicas; ser indicado ou nomeado a prêmios reconhecidos; estar presente em feiras de arte de renome; todos estes espaços majoritariamente Ocidentais e no eixo Europa-EUA). Esse conjunto de fatores - mobilizadores de capitais nos termos bourdieusianos (BOURDIEU, 2016) - atuarão como marcadores de profissionalização e êxito das carreiras artísticas contemporâneas. Alain Quemin (2016, p. 14), ao analisar as listas e critérios de consagração artística de balizadores como Atfacts e KunstKompass (de 2012), argumenta que, "embora a maioria dos agentes prefiram acreditar que a nacionalidade, 0

2 Woodham (2017, p. 27), por exemplo, aponta que para cada "artista de marca" presente em Nova York, temos uma média de 5 mil criadores contemporâneos locados num eixo intermediário do campo da arte, cujos trabalhos são adquiridos por um montante médio de USD 56.500/ano. 
país ou o local de residência não exerçam qualquer influência à trajetória dos artistas para o sucesso", cinco países ${ }^{3}$ - todos Ocidentais - ainda representam sozinhos quase $80 \%$ dos artistas mais reconhecidos a nível internacional.

Resultado aproximado obteríamos ao vislumbrar a concentração de colecionadores importantes no mesmo eixo (MOREAU et al., 2016), ou ainda se computássemos as galerias e feiras de arte (VELTHIUS, 2007, 2012). Esse conjunto de dados corrobora uma desmitificação da errância artística, quando num mundo globalizado os artistas estariam se deslocando igualmente entre todos os espaços. Ao contrário, percebemos que, apesar da facilidade de circulação, ainda opera-se a estabilidade de centros irradiadores dos valores artísticos e simbólicos, e que os criadores contemporâneos - embora possam locomover-se - necessitam em alguma medida grafarem sua presença nesses espaços para obterem alguma relevância e êxito.

Montado esse quadro teórico que argumenta existir assimetrias e variações vigentes no universo das artes estipulando condições distintas de acesso e reconhecimento dos artistas, o objetivo central deste estudo - ainda panorâmico - é experimentar a validade desse argumento, sobretudo no que tange aos agentes oriundos de realidades geográficas de baixa aderência ou reconhecimento no espaço social da arte contemporânea mundial. Para tanto, tomaremos como objeto sociológico de análise a coleção de arte da Fondation Louis Vuitton, gerida e mantida pelo conglomerado de luxo $\mathrm{LVMH}^{4}$ em Paris, que tem na persona do bilionário Bernard Arnault ${ }^{5}$, sua figura central.

\footnotetext{
3 Na análise de Quemin (2016): EUA, Alemanha, Reino Unido, Suiça e França, respectivamente.

$4 \quad$ O conglomerado de luxo LVMH (surgido em 1987) opera seis ramos mercadológicos: vinhos e outras bebidas; vestuário e bens de couro; perfumaria e cosméticos; relojoaria e joalheria; varejistas de moda de luxo; e outras atividades (em sua maioria relacionadas à arte e às casas de leilão). Em 2019, tornou-se a maior empresa de luxo do planeta após incorporar a rede de joalherias Tiffany. Fonte: https://mercadoeconsumo.com.br/2019/11/26/grupo-lvmh-fecha-acordo-de-compra-bilionario-da-tiffany/ 5 Bernard Arnault (1949-) é um empresário francês do ramo do luxo, presidente e acionista majoritário do conglomerado LVMH, e de acordo com dados da Forbes de 2020, o segundo homem mais rico do mundo, Fonte: forbes.com/billionaires.
} 
Fondation Louis Vuitton, uma análise introdutória' ${ }^{6}$

Criada em 2006 como parte do programa de patronagem às artes do conglomerado do luxo LVMH e aberta oficialmente ao público em 24 de outubro de 2014, a Fondation Louis Vuitton ocupa uma extensa área no Bois de Bologne, em Paris, em edifício projetado pelo ganhador do prêmio Pritzker, o arquiteto Frank Gehry. Tendo como premissa tornar a "arte e cultura acessíveis a todos" e objetivos centrais de (i) promover as artes contemporâneas e históricas, (ii) criar uma experiência única para os visitantes, (iii) abrigar um diálogo com artistas, intelectuais e o público e (iv) inspirar o público através da beleza do edifício7; a coleção divide-se em quatro categorias - contemplativa, pop, expressionista, música e som - sendo composta atualmente por cerca de 330 obras produzidas por 120 artistas.

Responsável por comissionar e curar grandes mostras de peso internacional, a Fondation Louis Vuitton vem assumindo um papel bastante singular dentro da cena artística contemporânea mundial e, sobretudo, francesa, vide a extensiva cobertura midiática e as críticas elogiosas à exposição Le Monde Nouveau de Charlotte Perriand, que esteve em cartaz entre 02/10/2019 a 24/02/20208. Em um país com concentração altíssima de instituições de envergadura mundial, o reconhecimento dado a uma exposição montada por uma fundação privada é um sintoma do extenso trabalho realizado para grafar o lugar de pertença da coleção à arbitragem de um gosto lícito, das narrativas legitimadas da arte e da cultura reconhecida $(W U, 2006)^{9}$. Embora exista de fato um esforço e uma atenção direcionada a mulheres artistas, por vezes, esta concentra-se na promoção de um valor já

6 Todos os dados levantados nessa seção foram obtidos através de campo remoto no site mantido pela coleção, o que certamente provoca uma visão perspectivada. Não consideramos, por exemplo, outras artistas mulheres apresentadas em exposições individuais ou coletivas no espaço, mas apenas aquelas que pertencem ao acervo de consulta pública disponibilizado pela instituição. Fonte: https://www.fondationlouisvuitton.fr/fr.html, consulta em 05/03/2020 e 22/08/2020.

7 Tradução nossa para: promouvoir la création d'hier à aujourd'hui; créer une expérience unique pour les visiteurs; ouvrir les dialogues avec les artistes, les intellectuels et tous les publics; emouvoir par la beaute du batiment; respectivamente. Fonte: https://www.fondationlouisvuitton.fr/fr.html.

8 https://www.fondationlouisvuitton.fr/fr/expositions/exposition/charlotte-perriand.html

9 Wu (2006) demonstra o trabalho realizado por estas coleções ao contratarem curadores importantes, críticos de arte, financiarem catálogos e anúncios em revistas especializadas. Um dispêndio de capital financeiro que somente grandes coleções corporativas podem realizar, e que desdobra-se numa conversão de capital econômico em capitais culturais e artísticos. 
estabilizado. É o caso de Charlotte Perriand, mas também da japonesa Yayoi Kusama e da americana Cindy Sherman, artistas que, incontestavelmente, ocupam posições de destaque no universo da arte e receberam grandes retrospectivas na fundação. Visando uma cartografia mais precisa da representação feminina na coleção, caminhamos no sentido contrário a essas mostras blockbusters, isto é, uma verificação mais acirrada das diferenças de gênero e das geografias de nascimento ${ }^{10}$ dos artistas em seu acervo a partir de um estudo estatístico básico"11 (Gráfico 01).

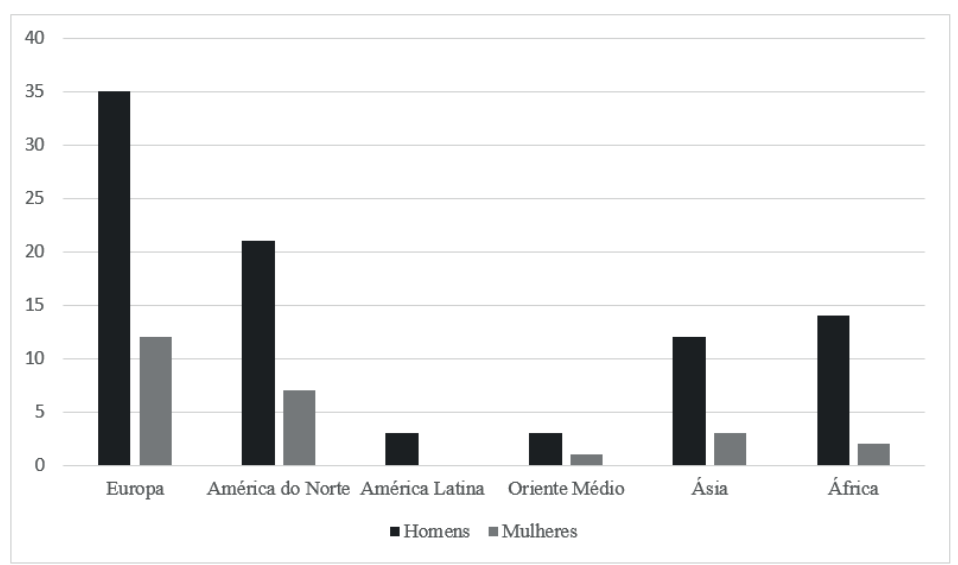

Gráfico 01 - № de artistas colecionados pela fundação, por gênero declarado e origem geográfica (local de nascimento). Fonte: Autoria própria ${ }^{12}$.

Uma breve leitura matemática dessas informações permite-nos constatar - sem precisar maiores variáveis - que a coleção (divulgada em seus meios eletrônicos) compõe-se de um volume de 77,9\% de artistas autodeclarados do sexo masculino e $22,1 \%$ de artistas autodeclaradas do sexo feminino. Em relação à origem geográfica desses atores são 41,6\% europeus; $24,7 \%$ norte-americanos; $14,1 \%$ africanos; $13,3 \%$ asiáticos; $3,53 \%$ oriundos do Oriente Médio e 2,6\% latino-americanos. Não há registro de

10 O local de nascimento não replica-se em local de trabalho. A maioria destes artistas formaram-se e vivem em cidades do eixo EUA-Europa.

11 Base de dados de 113 artistas colecionados pela fundação. Levantamento realizado em 05/03/2020.

12 É preciso salientar que o gráfico desenhado parte dos dados mantidos no site e que pode corresponder a uma realidade perspectivada ou disforme. A correção dessa curva de representação necessitaria de uma investigação sistemática no acervo físico da coleção. Apesar de qualquer deformação dos dados, chamamos atenção à discrepância existente, sobretudo quando inseridas as variáveis gênero e origem geográfica. 
artistas provenientes da Oceania. Dos artistas de origem europeia, três nacionalidades destacam-se: franceses, alemães e britânicos. Os franceses são maioria, 22,1\%.

Esses dados ilustram precisamente a matriz eurocêntrica e norteamericana das instituições e atores de legitimação da arte contemporânea. Uma vez que concentram as ferramentas discursivas de promoção, é esperado que essas geografias também concentrem os artistas de maior circulação, reconhecimento e representação no universo artístico global (QUEMIN, 2002; MOULIN, 1992, 2007). Embora tensões e disputas surjam, esses núcleos duros continuam a operar os processos de produção de legitimidade, de construção do gosto e arbitragem no quesito arte contemporânea de nível internacional. Não é de todo o espanto quando numa listagem dos vinte e cinco artistas contemporâneos mais vendidos do mundo entre 2011 e 2015, quatorze sejam europeus ou norte-americanos, ou que das cinco galerias de arte consideradas mais representativas, quatro tenham origem europeia e uma origem estadunidense (WOODHAM, 2017, pp. 37-41). Se tomarmos ainda as listagens de 2012 da Artfacts, trabalhadas por Quemin (2016), perceberemos que entre os 100 artistas mais importantes do mundo, 96 criam em um único país e apenas 4 ficam entre dois países, desses, $80 \%$ provenientes de cinco nações. Apesar de muitos serem originários de outras geografias, residem e trabalham unicamente em países ocidentais tidos como importantes ou mais legitimados na arte contemporânea.

Nesse contexto, assomamos aqui em adição ao conceito de campo artístico, a ideia de Universo como postulada por Ortiz (2019), de um território específico constituído por pontos descontínuos conectados pela mesma intensão simbólica, ou seja, "um universo é um território (...) constituído por indivíduos, instituições, práticas e objetos. Trata-se, portanto, de um todo, totalidade na qual a integração das partes que o compõem faz-se necessária, elas encontram-se interligadas" (ORTIZ, 2019, p. 65). De certo modo, essa ideia sobrepõe-se a uma noção abstrata; representa em alternativa o desenho geográfico de práticas, atores e locais, que dispersos territorialmente, participam da constituição de um mesmo princípio ou valor simbólico. Assim, se toda identidade ou elaboração de valor é um constructo 
simbólico feito a partir de um referente, essa concepção nos auxilia a compreender que os referentes estão postos, tecidos narrativamente nesse espaço social, cabendo ao artista percorrê-los em busca de validação ou produção de relevância para a arte contemporânea. O roteiro está dado, e desafiá-lo pode ser pouco efetivo.

Importa destacarmos, portanto, que (i) o campo artístico produzse na disputa pelo poder narrativo; é essa discursividade mantida por determinados atores que gera os locais legítimos de pertença; (ii) os pontos de pertença - físicos ou simbólicos - que auxiliam na elaboração do que compreendemos como êxito artístico compõem um universo, isto é, um conjunto de coordenadas ocupadas com a intenção de erigir um constructo simbólico de identidade, valor e relevância; e (iii) as assimetrias são uma máxima desse cenário, logo, mesmo participando de um mercado global, a cultura - e as artes em seu seio - respondem a uma lógica outra, a da mundialização e fazer coincidir esses valores constitui parte da produção de legitimidade da carreira artística. Assim, criadores contemporâneos por vezes são impelidos a circular através desses pontos postos de um universo de modo a chancelarem seu mérito e pertinência para o campo das artes, é no preenchimento dessas coordenadas - todas produtoras de uma mesma intenção simbólica - que o artista erige seu sucesso na arte contemporânea.

Parece existir, isto posto, uma superposição entre alguns espaços geográficos e os espaços de concatenação simbólica. Quando retomamos esses dados, o que nos captura a atenção não é somente a desigual estrutura que certifica os artistas do norte-global em detrimento dos demais; mas também como e quais artistas de outros centros acessam e mantêmse nessa esfera simbólica. Assim, parece mais elucidativo voltarmos nossa investigação aos grupos "minoritários" que acedem a esse reconhecimento que aos grupos coesos oriundos dos espaços já consagrados. Propondo uma breve cartografia das condições de acesso e êxito na arte contemporânea, destacaremos e analisaremos a trajetória de três artistas migrantes ${ }^{13}$ colecionadas pela fundação Louis Vuitton, a libanesa Mona Hatoum (1952-), a queniana Wangechi Mutu (1972-) e a sul-africana Zanele Muholi (1972-).

13 Entendemos artistas migrantes como aqueles que deslocam-se para outras geografias em busca de formação escolar, ou que trabalham exclusivamente - ou com frequência - em países que não os seus de origem. 


\section{As mulheres na FLV: perfilando trajetórias de artistas migrantes}

Antes de perfilarmos, de fato, a trajetória e o acesso dessas mulheres artistas aos espaços de consagração da arte contemporânea, é preciso antes redescobrirmos a ideia de crença - no sentido sociológico - nas artes, e mais, seus módulos de produção. Adotaremos aqui o senso desenvolvido pelo sociólogo francês Pierre Bourdieu que nos auxiliará a deflagrar essas instâncias e processos. Pois bem, a crença, em Bourdieu, é tributária de uma série de reflexões anteriores, consolidadas no pensamento sociológico e antropológico clássicos: 'o conformismo moral e lógico' de Émile Durkheim; a 'economia das reciprocidades simbólicas' de Marcel Mauss; e ainda o 'carisma' em Max Weber. O estudo da crença, como por ele estipulada, atua no desvelo dos processos de interiorização oculta de princípios sociais produtora de uma credibilidade intrínseca - natural às coisas da fé -, e extrinsecamente elaborada (BOURDIEU 2004; SETTON, 2017).

Termo contextualizado tanto nas ações individuais quanto coletivamente organizadas, a crença - e sua produção - participam das regras do jogo, e não se reduz a "um ato de fabricação material, mas (...) um conjunto de operações que tendem a assegurar a promoção ontológica e a transubstanciação do produto" (BOURDIEU, 2004, p.168). Assim, se por um lado a arte necessita de condições materiais para se manifestar, a elaboração de seu valor social será operada aditivamente nesse outro espaço simbólico que organiza e assegura a legitimidade. A disputa pelo monopólio da legitimidade contribui para reforçar a sua própria função, isto é, lança luz ao "efeito mais bem oculto desse conluio invisível, a produção e reprodução permanentes da illusio, adesão coletiva ao jogo que é a um só tempo causa e efeito da existência do jogo" (BOURDIEU, 1996, p.192).

A crença se produz, portanto, na manutenção da illusio, das regras do jogo, e é, discursivamente elaborada e dependente de um espaço social coletivo. Partindo da noção maussiana de que o poder do mago acoplase resolutamente ao grupo mágico, Bourdieu argumenta que o artista 
que, ao acrescentar seu nome em um ready-made confere ao objeto um valor sem relação direta com seu custo de fabricação, deve sua eficácia mágica a toda a lógica do campo artístico "que o reconhece e o autoriza; seu ato não seria nada mais que um gesto insensato ou insignificante sem o universo dos celebrantes e dos crentes que estão dispostos a produzilo como dotado de sentido e de valor" (BOURDIEU, 1996, p. 195). Logo, a crença na serventia social da arte enraíza-se, resumidamente, em (i) na prática coletiva de promoção da mesma, produzida e reproduzida por aqueles que, ao possuírem capitais acumulados, passam a exercer uma função discursiva que a diferencia em detrimento de outras práticas; e (ii) na disputa constante pelo hegemonia narrativa - o discurso sobre a obra não é um adjuvante mas também um momento de elaboração da obra - que manifesta-se no poder acumulado por diferentes atores do campo, hierarquicamente dispostos e organizados (um conluio interessado) de modo a manterem sua posição e a crença naquilo que dizem.

Poderíamos ainda, e sem a profundidade que esta comparação merece, acentuar a promoção coletiva da arte como aquela descrita pelas ações em rede dos Art Worlds de Becker (1982), nos quais a arte é elaborada por um conjunto de agentes interessados, dispostos em uma teia comum, na qual as ações em um ponto reverberam em outro. Dessa forma haveria um interesse grupal pela manutenção da morfologia desse espaço social. De um modo ou outro, a ideia que trazemos de crença - e de sua produção - torna-se basilar para nossa análise. Ao perfilarmos a trajetória e êxito dessas mulheres artistas - de países considerados periféricos - no campo da arte legitimada, mostraremos que cada coordenada (física ou simbólica) ocupada por elas em sua formação e trabalho, participam - pelos seus capitais acumulados e pela crença anteriormente produzida e reproduzida na autenticidade desses espaços sociais - na elaboração coletiva da legitimidade de suas obras para a arte; um cenário onde a migração - para sítios já legitimados - parece ser um dos pontos cruciais para seu reconhecimento e desmistificadora de uma noção de errância artística globalizada. 
Partiremos, primeiro, de uma rápida compilação biográfica de cada uma dessas três artistas presentes no acervo da Fondation Louis Vuitton:

Mona Hatoum: Nascida no Líbano em 1952. Vive e trabalha em Londres desde 1975. Formou-se na Slade School of Art (University College London). Sua obra está presente em acervos do Centre Georges Pompidou (Paris), Tate (Londres), MoMA (Nova York) e Guggenhein (Nova York). Realizou 121 exposições individuais em museus de todos os continentes e em galerias. Recebeu cinco prestigiosos prêmios entre estes, o Joan Miró Prize (2011) e Whitechapel Gallery Art Icon (2018). Participou de inúmeras bienais, com destaque para a Bienal de Veneza e a Documenta de Kassel. Possui diversos livros publicados sobre o seu trabalho e é comercialmente representada por galerias majors como a White Cube (com espaços em Londres, São Paulo e Hong Kong) ${ }^{14}$.

Wangechi Mutu: Nascida no Quênia em 1972. Vive e trabalha em Nova York. Possui formação pela Yale School of Art. Sua obra está presente em muitos acervos dos EUA e Europa, com destaque para Tate (Londres) e MoMA (Nova York). Realizou 21 exposições individuais em grandes museus e galerias (destaque para San Francisco Museum of Modern Art (SFMOMA) e Brooklyn Museum) e mais de uma centena de exposições coletivas. Participou de inúmeras bienais, com destaque para a Bienal de Veneza e a Documenta de Kassel. É comercialmente representada por galerias majors, com destaque para Saatchi Gallery (Londres) e Victoria Miró (Londres, Nova York e Veneza) ${ }^{15}$.

Zanele Muholi: Nascida na África do Sul em 1972. É professora honorária da Universidade de Bremen, na Alemanha. Formou-se pela Ryerson University, em Toronto no Canadá. Premiada com uma bolsa honorária Royal Society Photographic (Reino Unido) e com o grau

14 https://www.tate.org.uk/art/artists/mona-hatoum-2365/who-is-mona-hatoum.

15 https://www.artsy.net/artist/wangechi-mutu 
Chevalier pela Ordre des Arts et des Lettres (França). Realizou exposições solo em grandes museus (com destaque para Stedelijk Museum Amsterdam, Tate, Brooklyn Museum). Possui obras no acervo do MoMA (Nova York) e participou de diversas bienais, com destaque para a Bienal de Veneza e a Documenta de Kassel. É representada por galerias como a Yancey Richardson, em Nova York'16.

Ao realizarmos esse perfilamento podemos assinalar uma série de coincidências ou proximidades que não possuem nada de aleatórias. As três provêm de países cujas realidades artísticas são instáveis em comparação com um dado campo legítimo, todas elas migram e realizam suas formações profissionais em países do norte-global (Europa ou América do Norte) e vivem a maior parte do tempo - ou exclusivamente - trabalhando nesses mesmos locais. São representadas por grandes galerias comerciais com sedes em Londres e Nova York, possuem obras em importantes acervos de museus europeus e americanos, e participam de mostras consideradas altamente prestigiosas - Bienal de Veneza e Documenta de Kassel. Se tomarmos algumas dessas variáveis como pontos de convergência, poderíamos desenvolver uma cartografia simples de deslocamentos que são, por vezes, físico-simbólicos, participando da construção da ideia de êxito e profissionalização artística. Tomemos a nível de ilustração os seus locais de formação, cidades em que trabalham, presença em acervos reconhecidos e participação em bienais de grande repercussão midiática (Gráfico 02). 


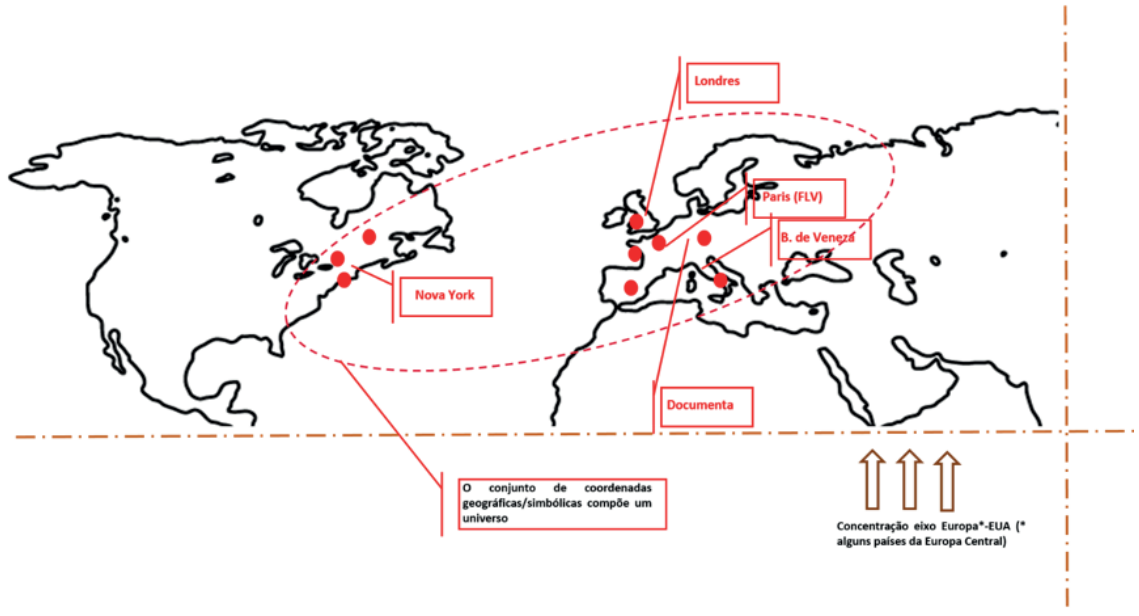

Gráfico 02 - Ilustração dos espaços sociais ocupados pelas artistas e composição de um possível universo simbólico. Fonte: Autoria própria.

Ao encaramos essa mapografia simbólica, torna-se preciso retomarmos a ideia de universo proposta por Ortiz. Para o sociólogo, a produção do valor simbólico não se encontra diluída, mas concentrada. Por exemplo, o luxo (e seu universo) não está em se visitar Paris ou Tóquio, mas na frequência a determinadas ruas ou locais específicos inseridos nessas realidades geográficas (ORTIZ, 2019). O mesmo poderíamos aplicar para o universo da arte. A crença no valor superior de uma prática não incide simplesmente na noção de pertença a uma cidade - essas artistas nada seriam se fossem apenas criadoras anônimas vivendo em Londres ou Nova York mas na entrada assegurada a pontos singulares locados nessas realidades (a Tate, o MoMA, Georges Pompidou, etc). Os pontos que destacamos no mapa, bastante comuns entre suas trajetórias, ratificam essa operação, e a linha que se desenha entre eles confirma o universo simbólico (que é a um só tempo geográfico e discursivo) de elaboração de suas legitimidades. Não é toda Paris, mas a presença no acervo do Pompidou, nem toda Nova York, mas a presença nos acervos do MoMA e do Metropolitan e a representação por galerias locadas na Fifith Avenue no Upper East Side. 
Ademais, se os diferentes tipos de capital - com enfoque no artístico e simbólico - podem ser compreendidos como uma espécie de olhar depositado sobre um sujeito ou uma prática pelos grupos coletivizados, notamos que esses atores e instituições geograficamente localizadas do universo da arte assumem o papel de mediadores e outorgadores (BOURDIEU, 2007). Assim, poderíamos traçar uma superposição entre valores artísticos e coordenadas geográficas - de educação, formação, trabalho e venda dessas artistas - que acabam por confirmar que os critérios de sagração e êxito na arte contemporânea interdependem mais das relações tratadas na experiência da distribuição desses valores no espaço social ou de "um microcosmo particular" (SAINT MARTIN; LANCIEN, 2007) que da qualidade estética e sensível das obras. Nosso argumento não é chauvinista ao pensar a arte como uma narrativa unicamente interessada e fabricada através de um conluio. Entendemos claramente que o pensamento fabular, os usos de novos dispositivos e os avanços estéticos por parte dos artistas assumem papel preponderante em seu trabalho; contudo, indicamos que essa dimensão não representa necessariamente aquela fulcral para a determinação de seu êxito. Indicamos que por vezes torna-se incontornável contabilizarmos as geografias simbólicas dos núcleos irradiadores da crença e a passagem desses atores por estes espaços como determinantes para sua profissionalização e sobrevivência artística, o que também explicaria a condição de imigrantes de muitos criadores que desejam adentrar esse espaço social.

Se voltarmos aos artistas da FLV cuja origem geográfica é não europeia ou norte-americana, perceberemos que parte considerável se encontra nessa realidade. Da representação africana, por exemplo, muitos irão estudar em universidades de notoriedade para o universo artístico, provêm de ex-colônias francesas sendo, portanto, francófonos, e em determinados casos expuseram tardiamente ou ainda não expuseram em seus países de origem, apresentando seus trabalhos primeiramente em espaços mais consolidados da arte contemporânea. Essa realidade corrobora mais uma vez a distribuição assimétrica das narrativas legitimadoras da arte, 
de uma história da disciplina eurocentrada e que incorpora o Outro - de forma generalizada e sem as problematizações que o tema carece - como artistas da diáspora ou a partir do interesse por um dado exotismo. Nesse sentido, a condição de migrante surge como uma espécie de solução epistemológica da práxis artística, um modo de se ampliar as chances e as apostas no jogo da arte; ver e ser visto; circular e acumular capitais que facilitem a negociação do êxito. Não despropositadamente percebemos no mapa supracitado que, apesar dos locais de nascimento indicarem um pertencimento sul, a formação e profissionalização dessas artistas thes impele a um movimento bastante concentrado no eixo EUA e alguns países da Europa Central (e aqui corroboramos a avaliação de Quemin $(2002,2016)$ das listas de importância geográfica: Alemanha, França, Reino Unido, Itália, Suíça).

Importa recordarmos que embora essas três artistas não tenham recebido grandes mostras individuais na fundação (diferentemente de Yayoi Kusama e Cindy Sherman, que além de ocuparem posições de destaque nas listagens de relevância artística de veículos especializados também figuram nos relatórios de sucesso econômico ${ }^{17}$ ), sua posição no campo da arte é incontestável. Pertencem a uma elite artística que circula e é promovida por instituições mundiais, suas obras tem entrada assegurada em galerias importantes e nos leilões noturnos da tríade Sotheby's/Christie's/Phillips, publicam-se livros e catálogos sobre suas obras, são contempladas por premiações importantes. Se ainda não são stars, caminham para ocuparem tais posições (QUEMIN, 2013).

Essa breve cartografia das condições de acesso e êxito artístico, nos auxilia a deflagar - em parte - os critérios envolvidos na consagração das carreiras da arte contemporânea, isto é, um modus operandi de uma lógica legitimadora, de um estado das coisas que tende a ser replicado. Pensar nas condições de acesso de Mona Hatoum, Wangechi Mutu e Zanele Muholi a uma prestigiosa coleção internacional como a mantida pela Fondation Louis Vuitton, não caminha no sentido de questionar a validade dessas artistas e de

17 Nos referimos aqui às listas anuais de agências especializadas em medir a relevância artística dos criadores contemporâneos com destaque para KunstKompass, ArtReview, Artfacts, etc. 
seus trabalhos, ao contrário, tratando temas como as políticas de gênero, a guerra e a africanidade, essas artistas são pilares de resistência dentro de um world art system. Olhar e refletir sobre suas trajetórias nos auxilia, todavia, a lançar luz sobre o funcionamento azeitado às práticas e às narrativas do universo artístico, um diagnóstico que serve como prognóstico aos artistas que pretendem adentrar esse espaço social.

\section{Conclusão}

Investigar a arte, suas instituições e mercados é sempre uma tarefa desafiadora. Independentemente do interesse e esforço empregado, o sociólogo que se dedica a esses estudos descreverá sempre uma abordagem perspectivada e obliterada pelas muitas zonas cinzentas desse universo. Criam-se análises de mercado, mas estas restringem-se apenas às vendas públicas, sublimando todas as negociações realizadas a portas fechadas e que possivelmente nunca serão acessadas. Discute-se o programa curatorial de uma instituição mas nunca se sabe por completo o que se passa nas reuniões de suas diretorias e a força que seus patrocinadores exercem na tomada de decisões. No entanto, embora representativas de uma das faces prismáticas dessas relações, essas abordagens não são menos objetivas e fornecem pistas bastante importantes para a compreensão sociológica da prática artística na contemporaneidade.

Trabalhos como o do sociólogo francês Alain Quemin $(2002,2016)$ e do sociólogo holandês Olav Velthius (2007, 2010, 2012), nos auxiliam a quantificar os procedimentos de rankeamento artístico, sobretudo ao contabilizarem as listagens que regem o valor artístico e os procedimentos de venda nos mercados primários e secundários. Moulin $(1985,2000)$ nos instrumentaliza a pensar a composição de um ecossistema artístico e o locus funcional dos artistas nessa morfologia social. Moureau e SagotDuvaroux (2016) organizam a reflexão sobre o papel dos colecionadores na elaboração da crença e da legitimidade da arte contemporânea mundial, sobretudo após a virada do milênio e de suas mitologias globalizantes. 
Estes estudos compõem o terreno basilar para problematizações outras que são agora imperativas. Poderíamos citar a necessidade imediata de para além de uma confiabilidade nos medidores tradicionais de revistas e agências especializadas - discutirmos a composição narrativa dos próprios critérios definidores dessas listagens (a partir de que medidores se consagra uma trajetória? Quem são os sujeitos e as equipes que determinam tais variáveis? Quais os seus backgrounds e a crença que reproduzem?); ou ainda contabilizarmos os novos fluxos migratórios como responsáveis pela alteração das paisagens culturais de cidades globais.

Seguramente, quando analisamos determinadas trajetórias de sucesso na arte contemporânea, a migração para um espaço simbolicamente legitimado parece ser um fator ainda bastante recorrente. Migrar é um direito humano assegurado (embora não o seja assim na prática), e são muitas as comunidades que movidas por questões próprias deslocam-se a outros sítios. Os artistas também participam, e até mais, desses movimentos (GUERRA et al., 2020). O que descrevemos ao longo deste trabalho não é um libelo contrário à migração artística. Buscamos justamente o oposto, mostrar que esta torna-se, em diversas ocasiões, sistêmica, um modo operante de produção de distinção e legitimidade.

Seria possível delinear um futuro em que a migração seja uma escolha e não unicamente movida pela grafia de um território simbólico sem o qual o êxito na arte contemporânea é quase impossível? Seria viável imaginarmos uma distribuição mais igualitárias das instâncias de legitimação para outras geografias? Se a reflexão sobre o campo discursivo é o modo de clarificarmos a produção do conceito e da sobredeterminação da legitimidade e do gosto corrente, os estudos sobre o êxito e a consagração das carreiras artísticas contemporâneas tornam-se a ferramenta de desvelo da cultura como prática social hierarquizada e - ainda - artificialmente centrada. 


\section{Referências}

BECKER, Howard. Art Worlds. Berkeley: University of California Press, 1982.

BOURDIEU, Pierre. A produção da crença: contribuição para uma economia dos bens simbólicos. Porto Alegre: Zouk, 2004.

BOURDIEU, Pierre. As Regras da Arte: Gênese e Estrutura do Campo Literário. São Paulo: Cia das Letras, 1996.

BOURDIEU, Pierre. La noblesse: capital social et capital symbolique. In: LANCIEN, Didier; SAINT MARTIN, Monique (Orgs.) Anciennes et nouvelles aristocracies de 1880 à nous jours. Paris: Ed. MSH, 2007.

BOURDIEU, Pierre. O amor pela arte: os museus de arte na Europa e seu público. Porto Alegre: Zouk, 2016.

FOUCAULT, Michel. The order of things. Nova York: Vintage Books, 1971.

GUERRA, Paula; HOEFEL, Maria da Graça; OSÓRIO SEVERO, Denise; SOUSA, Sofia. Women on the Move. Contributions to the aesthetic-political activism approach of Brazilian migrant women. Cahier du MMMOC, v. 21, 2020.

LANCIEN, Didier; SAINT MARTIN, Monique (Orgs.) Anciennes et nouvelles aristocracies de 1880 à nous jours. Paris: Ed. MSH, 2007.

MOULIN, Raymonde. L'Artiste, l'instituition et le marché. Paris: Flammarion, 1992.

MOULIN, Raymonde. O Mercado da Arte: mundialização e novas tecnologias. Porto Alegre: Zouk, 2007.

MOULIN, Raymonde. Sociologie de l'Art. Paris: L'Harmattan, 2000.

MOULIN, Raymonde. Les artistes: essai de morphologie sociale. Paris: La dcoumentation française, 1985.

MOUREAU, Nathalie. Colecionadores de arte: desde o outro lado do espelho. In: BULHÕES, Maria Amélia; VARGAS, Nei; FETTER, Bruna. Livro do $2^{\circ}$ Simpósio Internacional de Relações Sistêmicas da Arte. Porto Alegre: Editora UFRGS, 2020.

MOUREAU, Nathalie; SAGOT-DUVAUROUX, Dominique; VIDAL, Marion. Collectionneurs d'art contemporain. Paris: Ministère de la Culture, 2016.

MOUREAU, Nathalie; SAGOT-DUVAUROUX. Le marché de l'art contemporain. Paris: La Découverte, 2016.

ORTIZ, Renato. Mundialização e Cultura. São Paulo: Brasiliense, 1998. 
ORTIZ, Renato. O próximo e o distante: Japão e a modernidade-mundo. São Paulo: Brasiliense, 2000

ORTIZ, Renato. O Universo do Luxo. São Paulo: Alameda, 2019.

QUEMIN, Alain. A distribuição desigual do sucesso em arte contemporânea entre as nações: uma análise sociológica da lista dos 'maiores' artistas do mundo. In: VILLAS-BÔAS, Glaucia; QUEMIN, Alain (Orgs.) Arte e vida social. Paris: OpenEdition, 2016.

QUEMIN, Alain. L'art contemporain international: entre les institutions et le marché. Paris: Jacqueline Chambon, 2002.

QUEMIN, Alain. Les stars de l'art contemporain. Notoriété et consécration artistiques dans les arts visuels. Paris: CNRS, 2013.

SETTON, Maria da Graça Jacintho. Crença. In: CATANI, Afrânio Mendes et al. Vocabulário Bourdieu. Belo Horizonte: Autêntica, 2017.

SIMIONI, Ana Paula. Campo artístico. In: CATANI, Afrânio Mendes et al. Vocabulário Bourdieu. Belo Horizonte: Autêntica, 2017.

THOMPSON, Don. The \$12 Million Stuffed Shark: The Curious Economics of Contemporary Art. Nova York: St Martins Press, 2008.

THOMPSON, Don. The Orange Balloon Dog: Bubbles, Turmoil and Avarice in the Contemporary Art Market. Nova York: Douglas \& Mclntyre, 2017.

VELTHIUS, Olav. Talking Prices: Symbolic Meanings of Prices on the Market for Contemporary Art. Princeton: Princeton University Press, 2007.

VELTHIUS, Olav; HAMELIJNCK, Rob. Front Desk / Back Office No.2: the secret world of galleries in 39 pictures and two texts. Londres: Idea Books, 2010.

VELTHIUS, Olav; LIND, Maria (Orgs.) Contemporary Art and Its Commercial Markets A Report on Current Conditions and Future Scenarios. Amsterdã: Metahaven, 2012.

WOODHAM, Doug. Art collecting today. Nova York: Allworth Press, 2017.

WU, Chin-Tao. A privatização da cultura: a intervenção corporativa nas artes desde os anos 1980. São Paulo: Boitempo, 2006. 